\title{
Prediction of Peat Forest Fires Using Wavelet and Backpropagation
}

\author{
Novera Kristianti ${ }^{1}$, Albertus Joko Santoso ${ }^{2}$, Pranowo ${ }^{3}$
}

\begin{abstract}
One of the causes of smog as well as climate damage, particularly in Palangka Raya, Center Kalimantan, are peat forest fires. There are a lot of losses inflicted by the smog including the increasing number of people who suffer respiratory infection (ARI) due to polluted air and any other related aspects. Peat fires are problematic to overcome because the locations of fires are difficult to be accessed. This paper focuses on building the system to predict the distribution of peat forest fire hotspots by utilizing satellite imagery. In designing the system for predicting the fire hotspots distribution, wavelet orthogonal was used as the initial processing of mapping the distribution of peat forest fire hotspots. Meanwhile, backpropagation method was used to identify the fire hotspot distribution patterns of peat forest fire in this system. From the result of the data tested which had been done for predicting the peat forest fire hotspots, the decomposition image obtained using Haar wavelet had the highest percentage of accuracy to recognize the fire hotspots, which is $\mathbf{9 0 \%}$. The recency of this system was its ability to predict the peat forest fire hotspots distribution which can be used as peat forest fires prevention, especially in Palangka Raya, Central Kalimantan.
\end{abstract}

Keywords - fire hotspots distribution, peat forest fire, wavelet orthogonal, backpropagation, Palangka Raya.

\section{INTRODUCTION}

Smog has occurred these recent years during dry seasons in Palangka Raya, Central Kalimantan, which brings negative impact to many parties. Ones of the causes of smog and climate damage that occur in Palangka Raya, Central Kalimantan, are peat forest fires. Forest fire is a disaster of forest destruction caused by fire [1], [2]. Forest fires generally occur in hot and dry areas [3]. The causes of these forest fires are human negligence such as overly hot weather conditions, climate change, and other factors [4]-[6].

Forest is one of the most significant keys for social, economic, and development aspects of a region. Therefore, forest fires pose a threat to the economic and environmental sectors [7]-[9]. Forest has a number of important roles in nature, including purifying water and storing carbon [10], [11]. The fact that forests are located in remote and large areas makes fires become difficult to be monitored and controlled [12]. Thus, field workers encounter difficulties very often to immediately cope with the peat forest fires because the fires occur far away from the access.

\footnotetext{
${ }^{1}$ Student, Universitas Atma Jaya Yogyakarta, Jalan Babarsari 44 Yogyakarta 55281 (tlp: +62-274-487711 ext 2224; fax: +62-274487748; e-mail: noverara@gmail.com)

${ }^{2,3}$ Lecturer, Universitas Atma Jaya Yogyakarta, Jalan Babarsari 44 Yogyakarta 55281 (tlp: +62-274-487711 ext 2224; fax: +62-274487748; e-mail: ${ }^{2}$ albjoko@staff.uajy.ac.id, ${ }^{3}$ pran@mail.uajy.ac.id)
}

Smog leads to many disadvantages in various aspects in life, including the number of people who suffer respiratory tract infections (ARI) which is increasing because of the contaminated air. Furthermore, students are also lagging behind because their schools are on holiday when the smog reaches the dangerous levels and the smog also causes the disruption of transportation facilities due to limited viewpoint.

The fact that peat forest fires occur every year continuously, fire prevention and mitigation are needed so as to minimize losses caused by the fires. A system for predicting peat forest fire hotspots distribution can be carried out as one of the steps to prevent peat forest fires in Palangka Raya, Central Kalimantan.

The study was conducted by comparing seventeen orthogonal wavelet: Daubechies family (db 1 to db 5), Coiflets family (coiflet 1 to coiflet 5), and Symlet s family (symlet 2 to symlet 8) for satellite images compression process. This research is expected to obtain the optimum type of wavelet in the compression process of peat forest fires satellite images.

Wavelet orthogonal namely Daubechies family ( $\mathrm{db} 1$ to $\mathrm{db}$ 5), Coiflets (coiflet 1 to coiflet 5), and Symlet s family (symlet 2 to symlet 8) were used to map the distribution of fire hotspots. Backpropagation method was also used to train the artificial neural network in the identification of fire hotspot distribution patterns in this system.

This paper is arranged into five parts. The first part is the introduction that discusses the background of the research problem and information. The second section is the study of satellite imagery, wavelet, and artificial neural network. The third part contains the research methodology and the satellite imagery processing. The fourth section has the content of the result of this research and the fifth part comprehends the conclusion of this research.

The data regarding forest fires was obtained using channels found in MODIS data. MODIS is designed to deliver reliable data in relation to the position of fire hotspots that has the greatest and most appropriate probability. It can also convey the information about forest fires multi-temporally [13].

The satellites launching which carried MODIS sensor has a wider coverage, so it performs better than NOAA-AVHRR [14]. Compared to NOAA-AVHRR, the capability of MODIS in measuring the surface temperature (LST) at low temperature measurement is also preferable [15].

The purpose of this study is to identify the patterns of fire hotspots using the Terra MODIS satellite data as well as to conduct the fire hotspot patterns recognition using Backpropagation method and wavelet orthogonal as the initial processing. 


\section{SATELlite IMAge, WAVELET, AND ARTIFICIAL NeURAL NETWORK}

Remote sensing technology can be used to detect the forest fire hotspots. One of them is by measuring the surface temperature using Landsat 8 data. The method is done by detecting hotspots seen from the remote sensing satellites [16].

Aside from utilizing Landsat data, there are many remote sensing satellites data which can be used. One of which is the NOAA satellite that encompasses a wide coverage for analyzing an area in a short time. The fire hotspots are used as the signs of forest fires that occurred [17].

The Terra-Modis satellite is a satellite that can be utilized to measure the surface temperature [18]. The advantage of using MODIS satellites is in terms of the surface temperature measurement quantity and quality which is increasing. The afternoon data taken using MODIS satellites performs closer to the maximum surface temperature of the soil, so the data tend to be more valid when it is used in soil moisture and dryness monitoring applications [19].

The data of active fire hotspots is obtained from MODIS satellite which then used for the input to map the time of fires occurrence. The information is then mapped to obtain the magnitude of forest fires, so that it can control the behaviour of fire based on climate, vegetation, and topography in the future [20].

The utilization of fire hotspots data taken from MODIS satellite is also useful in predicting forest fires. The fire hotspots data obtained from MODIS and Maxent algorithms is used to provide a quantitative understanding of environmental control. The information about the spatial distribution of fires is needed in the use of fire prevention [21].

Image processing can be utilized to detect forest fires. Fire pixels classification is used by means of a color-based rule. Color-based rules are then arranged to determine which pixels are classified as fire pixels. This is used in real-time forest fire monitoring systems [22]. Image processing with k-mean grouping and Haar wavelet takes a role to identify forest fires using ground surface temperature from the satellite images [8].

The use of backpropagation method in compressed images shows that this method can study changes in the reduction of signal redundancy and be able to recover compressed information [23]. The wavelet techniques and backpropagation artificial neural network models can be applied to forecast air quality. This is one step to protect public health by providing an early warning system for harmful air pollution [24].

\section{MethodOLOGY}

\section{A. Research Location}

This research was conducted in the city of Palangka Raya, Central Kalimantan. Geographically, the City of Palangka Raya is located at the coordinates $113^{\circ} 30^{\prime}-114^{\circ} 07^{\prime} \mathrm{E}$ dan $1^{\circ} 35^{\prime}-2^{\circ} 24^{\prime}$ S. The area of Palangka Raya city is approximately 2,853.49 Km2, as shown in Fig. 1 [25].

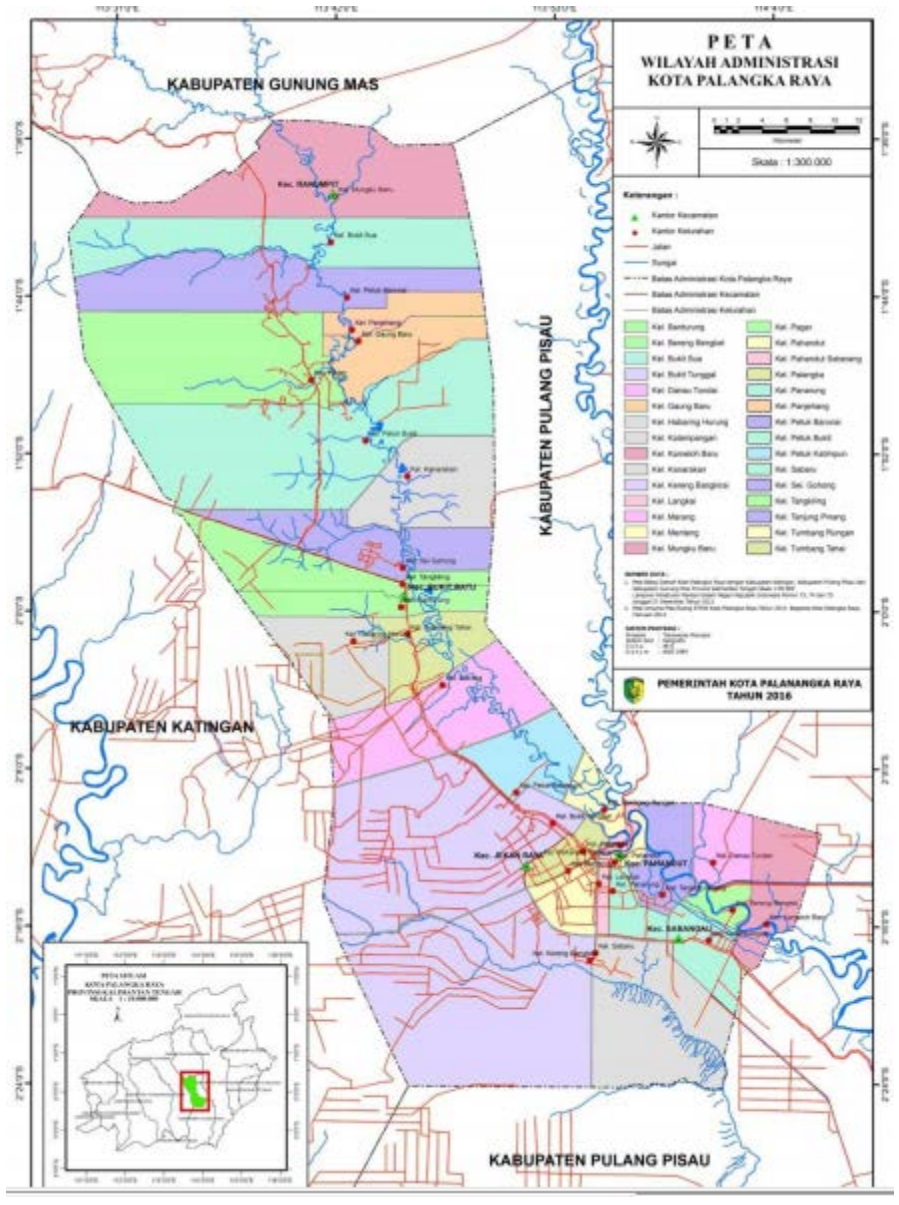

Fig. 1 The research location of Palangka Raya city [25].

\section{A. Stages of Research Process}

The first stage of this research was to input the Terra MODIS satellite image data. The data was obtained from the http://ladsweb.nascom.nasa.gov. Then, the processing of the Terra MODIS satellite image data was done. It encompassed the implementation of algorithm to obtain hotspots data analysis to be analyzed. Afterwards, several satellite images were compared to figure out the usefulness of the direction of the fire hotspots distribution.

The satellite image data which had been processed was then converted into binary image for image data input for the orthogonal wavelet decomposition process up to level $n$. Subsequently, network training step was carried out using the backpropagation method with the preliminary step of initializing the primary network weights. As the final step, the network was tested with the image data which had been trained and that had not been trained.

The steps performed as the basis of this research methodology are shown in Fig. 2.

\section{B. Satellite Imagery Processing}

The existing satellite imagery was then processed in order to obtain the image of surface temperature. The satellite imagery processing is shown in Fig. 3.

The stage of geometric correction were carried out for improving satellite imagery to suit the precise condition. It 
was done by repairing the damages and pixels of the images. Afterwards, the process of value conversion to be the radians value was done for converting the brightness temperature.

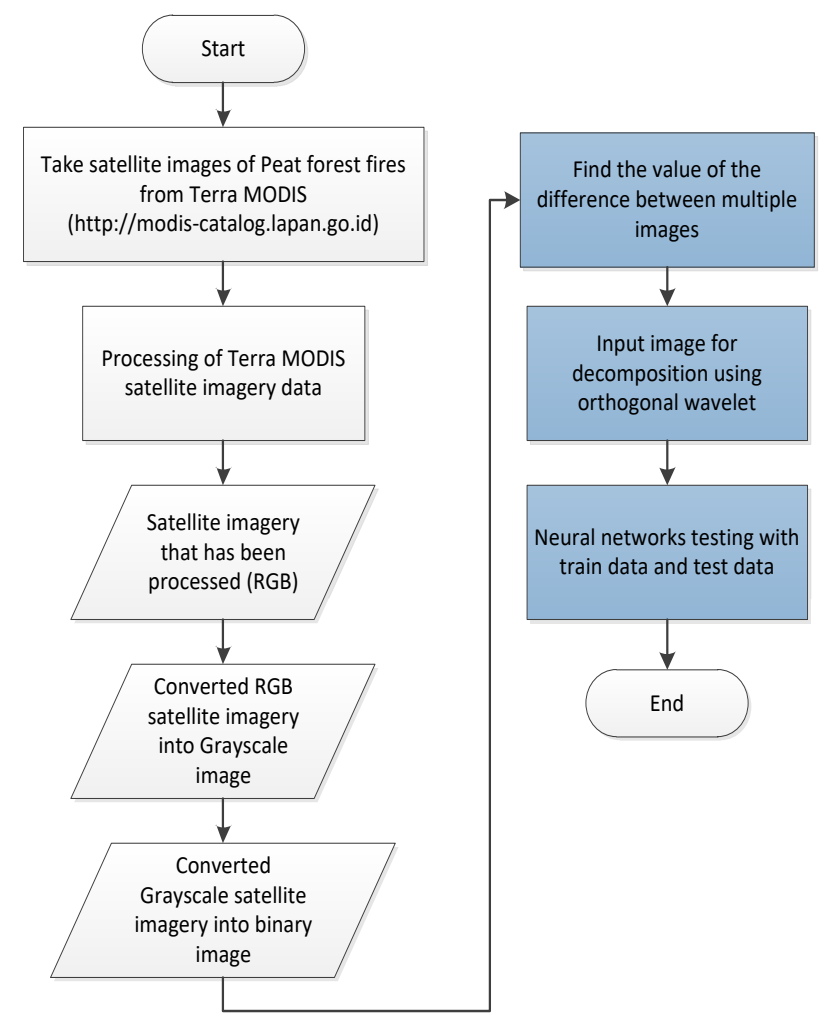

Fig. 2 Flowchart of the research methodology.

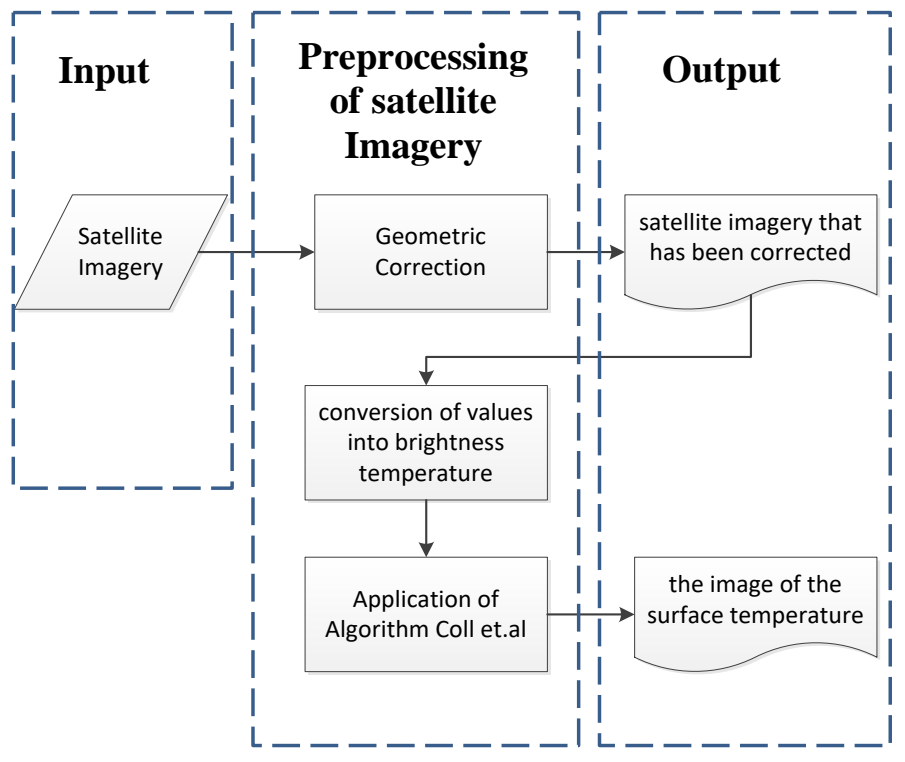

Fig. 3 Satellite imagery processing flow.

The application of the Coll et al. algorithm in a previous study was used to extract the temperature of soil surface from satellite images [26]. The Coll et al. algorithm is as follows.

$$
S P=T b 31+A(T b 31-T B 32)+B
$$

with

$$
\begin{aligned}
& A=1.0+0.58(T b 31-T B 32) \\
& B=0.51+40(1-e)-p A e
\end{aligned}
$$

with

$$
\begin{aligned}
& e=(e 31+e 32) / 2 \\
& A e=/ e 31-e 32 /=0.001, e 31=0.989 \\
& e 32=0.988
\end{aligned}
$$

note:

$$
\begin{array}{ll}
\text { SP } & =\text { land surface temperature } \\
\text { Tb31 } & =\text { canal } 31 \text { brightness temperature } \\
\text { Tb32 } & =\text { canal } 32 \text { brightness temperature }
\end{array}
$$

$P$ in the tropics is $50^{\circ} \mathrm{K}$.

In order to convert the SP value from Kelvin to Celsius, the result value was then reduced by 273 . The example of the result of satellite imagery which has been processed using ENVI 5.2 software by applying the steps described previously is shown in Fig. 4.

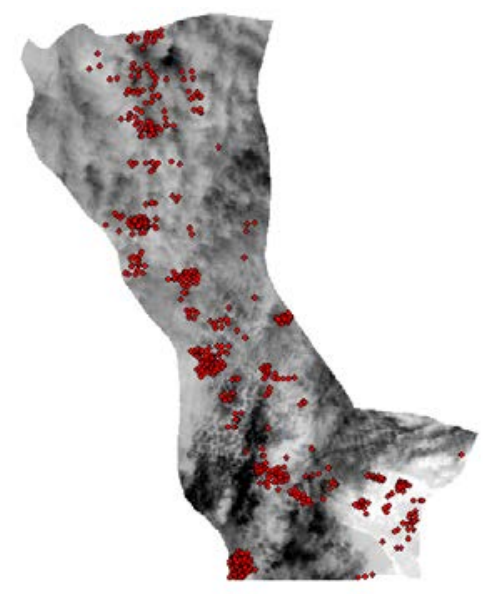

Fig. 4 Processed satellite imagery (1 September 2014).

\section{Wavelet orthogonal}

Orthogonal wavelet decomposition process was performed on the input image at this stage. There were seventeen types of orthogonal wavelet used namely Daubechies family (db 1 to $\mathrm{db}$ 5), Coiflets family (coiflet 1 to coiflet 5), and Symlet $\mathrm{s}$ family (symlet 2 to symlet 8 ).

The transformation of wavelet was used for the extraction process regarding the characteristics of an image, particularly in this study, for the extraction process of the fire hotspots characteristics on the images of peat forest fire.

Wavelet is a function based on $\psi(x)$, the mother wavelet. The two main operations of the underlying wavelet are translation and dilation.

1. The examples of translation are $\psi(x-1), \psi(x-2)$, and $\psi(x-b)$.

2. The examples of dilatation are $\psi(2 x), \psi(4 x)$, and $\psi(2 j x)$ [27].

The combination of translation and dilation operations produces wavelet formulas, as depicted in (2) [28].

$$
\psi a, b(x)=\frac{1}{\sqrt{|a|}} \psi\left(\frac{x-b}{|a|}\right)
$$


with

$a, b \in R ; a \neq 0$ ( $\mathrm{R}=$ Real-valued),

$a=$ dilation parameter

$b \quad=$ translation parameter

One of the decomposition processes using Haar wavelet at level 2 is shown through Fig. 5.

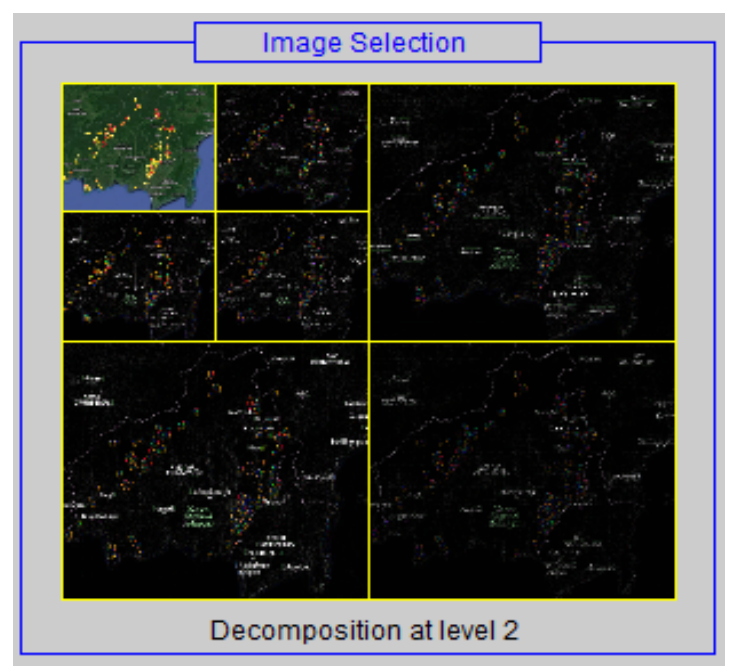

Fig. 5 Haar decomposition process at level 2.

\section{Artificial Neural Network: Backpropagation}

Artificial neural network is a simplified network of biological neural network. It employs the type of computing carried out by the human brain [29]. Backpropagation is a guided learning algorithm that trains multilayer of neural network that maps the relationship between target output and actual output [30].

A backpropagation algorithm was used for the fire hotspots of peat forest fires prediction. In this paper, a network training process was carried out using the initial weight initialization of the vector resulting from the transformation of the test image. The example of the layer for the backpropagation algorithm is shown in Fig. 6.

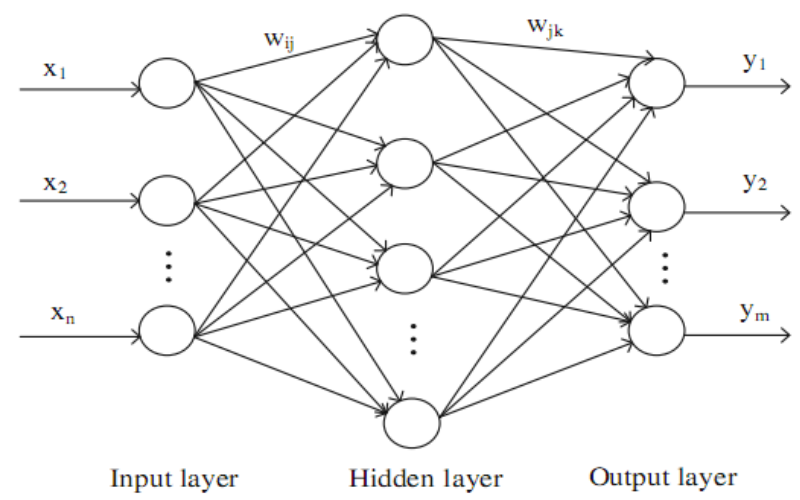

Fig. 6 Three-tier architecture of backpropagation.

\section{FINDINGS: PEAT Forest FIREs PREDICTION}

Wavelet selection was done for the process of predicting peat forest fires. The comparison by calculating the PSNR value was performed to the seventeen orthogonal wavelets namely the Daubechies family ( $\mathrm{db} 1$ to $\mathrm{db} 5$ ), the Coiflets family (coiflet 1 to coiflet 5 ), and the Symlet $s$ family (symlet 2 to symlet 8). PSNR is a benchmark for the similarity between the original images and the reconstruction images.

Trials were carried out on the three test images obtained by Haar, Coif1, and Sym2 which had the highest PSNR values for each family, as shown in Table I and Fig. 7. The formula for calculating the PSNR value was

$$
P S N R=20 x \log _{10} \frac{255}{\sqrt{M S E}}
$$

with

$$
M S E=\frac{1}{m n} \sum_{y=1}^{m} \sum_{x=1}^{n}\left(I(x, y)-I^{\prime}(x, y)\right)^{2}
$$

with

$$
\begin{array}{ll}
\text { PSNR } & =\text { Peak Signal to Noise Ratio } \\
M S E & =\text { Mean Square Error } \\
M & =\text { lines of the input image } \\
N & =\text { columns of the input image } \\
I(x, y) & =\text { original image } \\
I^{\prime}(x, y) & =\text { reconstruct image }
\end{array}
$$

TABLE I

HighEST PSNR RESULT FROM 17 TYPES OF WAVELET ORTHOGONAL

\begin{tabular}{|l|c|r|r|}
\hline & Test Image 1 & Test Image 2 & Test Image 3 \\
\hline Haar & 50.783 & 50.954 & 49.855 \\
\hline Coif1 & 50.090 & 50.232 & 49.245 \\
\hline Sym2 & 50.649 & 50.770 & 49.717 \\
\hline
\end{tabular}

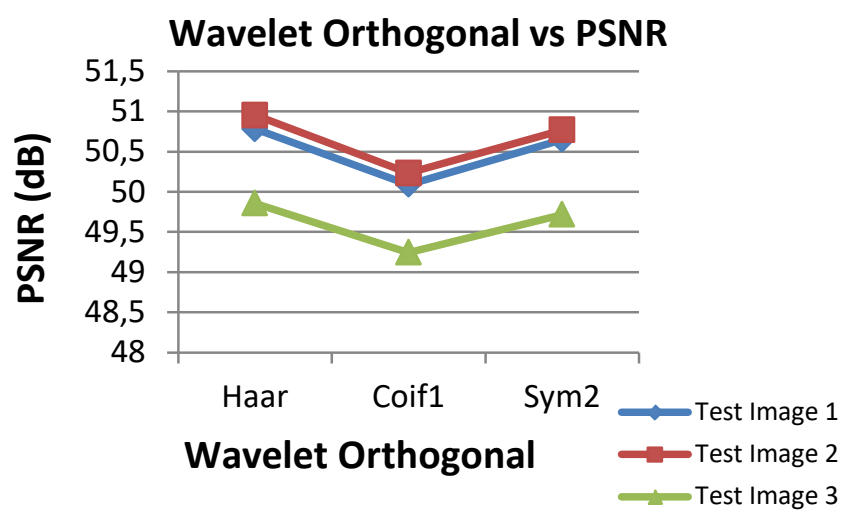

Fig. 7 Highest PSNR value.

From the Table I and Fig. 7, it can be seen from the PSNR results for orthogonal wavelets, namely Haar, Coif 1, and Sym2. The PSNR results are the highest results from each Daubechies family (db 1 to db 5), the Coiflets family (coiflet 1 to coiflet 5), and the Symlets family (symlet 2 to symlet 8 ).

Comparing the highest PSNR results, it is recorded that Haar had the perfect result for all test images. This was caused by the shorter the filter, the identification will also be simpler

The next step of the research was to do training using the backpropagation method. The first step needed was to initialize the primary weight of the network, establish the 
maximum epoch number, determine the target error, observe the learning rate, and momentum.

Three layers of backpropagation network structure were used in this paper. They were the input layer, hidden layer, and output layer. The training process to recognize the patterns well with the backpropagation network required the process of changing the weight in each input pattern and continuously changing the weight if the output was still not in line with the target.

The change in weight towards the backpropagation network in this paper used the momentum parameter $\mu$ limited to the range of 0 to 1 . The maximum epoch number was 20,000 with the learning rate between $0.1,0.5$, and 0.7 . The training process stopped with the desired goal condition, which was 0.0001 . The best process from each data training was used for the references of the testing phase. The best results were chosen based on the performance value and the smallest epoch value.

It was acquired from of the image training result that Haar wavelet performed well at the learning rate 0.7 , epoch 2.836 with MSE 0.000999 to achieve the target of 0.001 . Meanwhile, coif1 performed well at the learning rate 0.7 , epoch 2,467 with the MSE 0.00100 for reaching the target 0.001 and at the sym2 it was obtained that it worked well at the learning rate 0.5 , epoch 15,170 with the MSE 0.00173 for reaching the target 0.001 .

The wavelet processing using Haar, Coif 1, and Sym 2 in the process of predicting the fire hospots with the backpropagation learning was presented through the Table II, Table III, and Table IV.

TABLE II

The Result OF IMAge TeSting USING HAAR DeCOMPOSITION

\begin{tabular}{|l|r|r|r|c|}
\hline \multicolumn{1}{|c|}{ Image } & Target & \multicolumn{1}{c|}{ JST } & Error & Result \\
\hline 16 Agustus 2014.bmp & 0.5 & 0.48741 & 0.01258 & $\sqrt{ }$ \\
\hline 01 Sept 2014.bmp & 0.5 & 0.18569 & 0.31431 & $\times$ \\
\hline 17 Sept 2014.bmp & 0.5 & 0.58671 & -0.08671 & $\sqrt{ }$ \\
\hline 03 Okt 2014.bmp & 0.5 & 1.76770 & -1.26770 & $\sqrt{ }$ \\
\hline 04 Nov 2014.bmp & 0.5 & 0.75921 & -0.25920 & $\sqrt{ }$ \\
\hline 20 Nov 2014.bmp & 0.5 & 0.67792 & -0.17792 & $\sqrt{ }$ \\
\hline 03 Agustus 2015.bmp & 0.5 & 0.86416 & -0.36146 & $\sqrt{ }$ \\
\hline 19 Agustus 2015.bmp & 0.5 & 0.98497 & -0.48497 & $\sqrt{ }$ \\
\hline 06 Okt 2015.bmp & 0.5 & 1.32000 & -0.81996 & $\sqrt{ }$ \\
\hline 07 Nov 2015.bmp & 0.5 & 0.67792 & -0.17792 & $\sqrt{ }$ \\
\hline
\end{tabular}

It can be seen from the Table II that there were nine identified amount of data out of ten data. Therefore, the accuracy value was $90 \%$. The accuracy was calculated as follows.

$$
\begin{aligned}
\text { Accuracy } & =\frac{\text { Number of accurate data }}{\text { Number of test data }} \times 100 \% \\
& =\frac{9}{10} \times 100 \% \\
& =90 \%
\end{aligned}
$$

Table III shows six identified data, so the value of the accuracy was $60 \%$. The value was obtained from:

$$
\begin{aligned}
\text { Accuracy } & =\frac{\text { Number of accurate data }}{\text { Number of test data }} \times 100 \% \\
& =\frac{6}{10} \times 100 \% \\
& =60 \%
\end{aligned}
$$

TABLE III

The Result of IMAge Testing USING CoIflet 1 DeCOMPosition

\begin{tabular}{|l|r|r|r|c|}
\hline \multicolumn{1}{|c|}{ Image } & Target & \multicolumn{1}{c|}{ JST } & \multicolumn{1}{c|}{ Error } & Result \\
\hline 16 Agustus 2014.bmp & 0.4 & 1,18170 & -0.71362 & $\sqrt{ }$ \\
\hline 01 Sept 2014.bmp & 0.4 & 0,31978 & 0.14830 & $\times$ \\
\hline 17 Sept 2014.bmp & 0.4 & 0,36018 & 0.10791 & $\times$ \\
\hline 03 Okt 2014.bmp & 0.4 & 0,39167 & 0.07641 & $\times$ \\
\hline 04 Nov 2014.bmp & 0.4 & 0,47442 & -0.00633 & $\sqrt{ }$ \\
\hline 20 Nov 2014.bmp & 0.4 & 0,26032 & 0.20766 & $\times$ \\
\hline 03 Agustus 2015.bmp & 0.4 & 0,80142 & -0.33330 & $\sqrt{ }$ \\
\hline 19 Agustus 2015.bmp & 0.4 & 0,98497 & -0.48497 & $\sqrt{ }$ \\
\hline 06 Okt 2015.bmp & 0.4 & 0,85310 & -0.38501 & $\sqrt{ }$ \\
\hline 07 Nov 2015.bmp & 0.4 & 0,60237 & -0.13428 & $\sqrt{ }$ \\
\hline
\end{tabular}

TABLE IV

HASIL DARI PENGUJIAN CITRA DENGAN DEKOMPOSISI SYMLET 2

\begin{tabular}{|l|r|r|r|c|}
\hline \multicolumn{1}{|c|}{ Image } & Target & \multicolumn{1}{c|}{ JST } & \multicolumn{1}{c|}{ Error } & Result \\
\hline 16 Agustus 2014.bmp & 0.4 & 0,46648 & -0.02575 & $\sqrt{ }$ \\
\hline 01 Sept 2014.bmp & 0.4 & 0,20477 & 0.23595 & $\times$ \\
\hline 17 Sept 2014.bmp & 0.4 & 0,44350 & -0.00277 & $\sqrt{ }$ \\
\hline 03 Okt 2014.bmp & 0.4 & 0,44016 & 0.00056 & $\sqrt{ }$ \\
\hline 04 Nov 2014.bmp & 0.4 & 0,44016 & 0.00056 & $\sqrt{ }$ \\
\hline 20 Nov 2014.bmp & 0.4 & 0,44016 & 0.00056 & $\sqrt{ }$ \\
\hline 03 Agustus 2015.bmp & 0.4 & 0,22754 & 0.21319 & $\times$ \\
\hline 19 Agustus 2015.bmp & 0.4 & 0,50137 & -0.06061 & $\sqrt{ }$ \\
\hline 06 Okt 2015.bmp & 0.4 & 0,47261 & -0.03188 & $\sqrt{ }$ \\
\hline 07 Nov 2015.bmp & 0.4 & 0,44016 & 0.00056 & $\sqrt{ }$ \\
\hline
\end{tabular}

From Table IV, it can be observed that there were eight identified data. Hence, the accuracy value was $80 \%$ which obtained from:

$$
\begin{aligned}
\text { Accuracy } & =\frac{\text { Number of accurate data }}{\text { Number of test data }} \times 100 \% \\
& =\frac{8}{10} \times 100 \% \\
& =80 \%
\end{aligned}
$$

The utilization of orthogonal wavelet as the initial method of processing showed that the Haar wavelet produced images which resembled the original images. The results were found out from the PSNR calculation. The prediction of fire hotspots distribution using orthogonal wavelet and backpropagation had shown a reliable accuracy, which was $90 \%$.

\section{CONCLUSION}

The fire hotspot prediction system is expected to be used as a fire prevention and mitigation measure so as to minimize losses caused by fire. The fire hotspots prediction was used to identify the patterns of hotspots from peat forest fires. From the research which had been conducted, it was found that the use of orthogonal wavelets as the initial processing indicated the Haar wavelet produced the most similar images with the 
original ones. This was seen from the results of the PSNR calculation and prediction of the fire hotspots distribution using orthogonal and backpropagation wavelets which showed $90 \%$ accuracy.

\section{ACKNOWLEDGMENT}

We thank Universitas Atma Jaya Yogyakarta who provided insight and expertise that greatly supported the research.

\section{REFERENCES}

[1] S. Kanga and S.K. Singh, "Forest Fire Simulation Modeling using Remote Sensing \& GIS," International Journal of Advanced Research in Computer Science, Vol. 8, No. 2, pp. 326-332, May-June 2017.

[2] P.J. van Mantgem, J.C.B. Nesmith, M. Keifer, E.E. Knapp, A. Flint, and L. Flint, "Climatic Stress Increases Forest Fire Severity Across the Western United States," Ecology Letters, Vol. 16, No. 9, pp. 1151-1156, 2013.

[3] M. Castelli, L. Vanneschi, and A. Popovič, "Predicting Burned Areas of Forest Fires: An Artificial Intelligence Approach," Fire Ecology, Vol. 11, No. 1, pp. 106-118, 2015.

[4] A. Kaur, R. Sethi, and K. Kaur, "Comparison of Forest Fire Detection Techiques Using WSNs," International Journal of Computer Science and Information Technologies, Vol. 5, pp. 3800-3802, 2014.

[5] W.A. Hoffmann, E.L. Geiger, S.G. Gotsch, D.R. Rossatto, L.C. R. Silva, O.L. Lau, M. Haridasan, and A.C. Franco, "Ecological Thresholds at the Savanna - Forest Boundary: How Plant Traits, Resources and Fire Govern the Distribution of Tropical Biomes," Ecology Letters, Vol. 15, pp. 759-768, 2012.

[6] A. Ganteaume, A. Camia, M. Jappiot, J.S.-M. -Ayanz, M.L. -Fournel, and C. Lampin, "A Review of the Main Driving Factors of Forest Fire Ignition Over Europe," Environmental Management, Vol. 51, No. 3, pp. 651-662, 2013.

[7] L.K. Sharma, S. Kanga, M.S. Nathawat, S. Sinha, and P.C. Pandey, "Fuzzy AHP for Forest Fire Risk Modeling," Disaster Prevention and Management, Vol. 21, pp. 160-171, 2012.

[8] S. Anitha, S. Soujanya, and G.B. Rajkumar, "An Approach for Identifying the Forest Fire Using Land Surface Imagery by Locating the Abnormal Temperature Distribution," IOSR Journal of Computer Engineering (IOSR-JCE), Vol. 14, No. 3, pp. 06-12, 2013.

[9] N. Baranovskiy and M. Zharikova, "A Web-Oriented Geoinformation System Application for Forest Fire Danger Prediction in Typical Forests of the Ukraine," in Thematic Cartography for the Society, Cham, Switzerland: Springer, 2014, pp. 13-22.

[10] C. Yuan, Y. Zhang, and Z. Liu, "A Survey on Technologies for Automatic Forest Fire Monitoring, Detection, and Fighting Using Unmanned Aerial Vehicles and Remote Sensing Techniques," Canadian Journal of Forest Research, Vol. 45, pp. 783 - 792, March 2015.

[11] T.F. Keenan, D.Y. Hollinger, G. Bohrer, D. Dragoni, J.W. Munger, H.P. Schmid, and A.D. Richardson, "Increase in Forest Water-Use Efficiency as Atmospheric Carbon Dioxide Concentrations Rise," Nature, Vol. 499, No. 7458, pp. 324-327, 2013.

[12] P Ganesan, B.S. Sathish, and G. Sajiv, "A Comparative Approach of Identification and Segmentation of Forest Fire Region in High Resolution Satellite Images," 2016 World Conference on Futuristic Trends in Research and Innovation for Social Welfare (Startup Conclave), 2016, pp. 1-6.

[13] Y. Kaufman and C. Justice, "Algorithm Technical Background Document: MODIS Fire Products," MODIS Technical Document, pp. 177, November 1998.

[14] T. Ahmed, S.V. Naidu, D. Singh, and R. Balasubramanian, "An Approach to Detect Hotspots with INSAT-3D Data," 2015 National Conference on. IEEE Recent Advances in Electronics \& Computer
Engineering (RAECE), 2015, pp. 267-270.

[15] C.M. Frey, C. Kuenzer, and S. Dech, "Cross-Comparison of Daily Land Surface Temperature Products from NOAA-AVHRR and MODIS," in Thermal Infrared Remote Sensing, Dordrecht, Netherlands: Springer, 2013, pp. 215-231.

[16] Rajeshwari A. and Mani N.D., "Estimation of Land Surface Temperature of Dindigul District Using Landsat 8 Data," International Journal of Research in Engineering and Technology, Vol. 3, No. 5, pp. 122-126, 2014.

[17] J.A.M. Ruiz, D. Riaño, M. Arbelo, N.H.F. French, S.L. Ustin, and M.L. Whiting, "Burned Area Mapping Time Series in Canada (1984-1999) from NOAA-AVHRR LTDR: A Comparison with Other Remote Sensing Products and Fire Perimeters," Remote Sensing of Environment, Vol. 117, pp. 407-414, 2012.

[18] S.-B. Duan, Z.-L. Li, B.-H. Tang, H. Wu, and R. Tang, "Generation of a Time-Consistent Land Surface Temperature Product from MODIS Data," Remote Sensing of Environment, Vol. 140, pp. 339-349, 2014.

[19] L. Giglio, W. Schroeder, and C.O. Justice, "The Collection 6 MODIS Active Fire Detection Algorithm and Fire Products," Remote Sensing of Environment, Vol. 178, pp. 31-41, 2016.

[20] S. Veraverbeke, F. Sedano, S.J. Hook, J.T. Randerson, Y. Jin, and B. Rogers, "Mapping the Daily Progression of Large Wildland Fires Using MODIS Active Fire Data," International Journal of Wildland Fire, Vol. 23, No. 5, pp. 655-667, 2014.

[21] Q. Renard, R Pélissier, and B.R. Ramesh, "Environmental Susceptibility Model for Predicting Forest Fire Occurrence in the Western Ghats of India," International Journal of Wildland Fire, Vol. 21, pp. 368-379, 2012.

[22] V. Vipin, "Image Processing Based Forest Fire Detection," International Journal of Emerging Technology and Advanced Engineering, Vol. 2, No. 2, pp. 87-95, February 2012.

[23] G. Qiu, T. J. Terrell, and M.R. Varley, "Improved Image Compression using Backpropagation Networks," Workshop on Neural Network Applications and Tools, 1993, pp. 73-81.

[24] Y. Bai, Y. Li, X. Wang, J. Xie, and C. Li, "Air Pollutants Concentrations Forecasting Using Back Propagation Neural Network Based on Wavelet Decomposition with Meteorological Conditions," Atmospheric Pollution Research, Vol. 7, No. 3, pp. 557-566, May 2016.

[25] "Modul Kebakaran Hutan dan Lahan," Pemerintah Provinsi Kalimantan Tengah, pp. 1-67, 2017.

[26] T. Handayani, A.J. Santoso, and Y. Dwiandiyanta, "Pemanfaatan Data Terra Modis untuk Identifikasi Titik Api pada Kebakaran Hutan Gambut (Studi Kasus Kota Dumai Provinsi Riau)," Seminar Nasional Teknologi Informasi dan Komunikasi, 2014, pp. 461-467.

[27] G. Strang, "Wavelets and Dilation Equations: A Brief Introduction," SIAM Review, Vol. 31, No. 4, pp. 614-627, 1989.

[28] P. Rieder, J. Gotze, J.A. Nossek, and C.S. Burrus, "Parameterization of Orthogonal Wavelet Transforms and Their Implementation," IEEE Transactions on Circuits and Systems II: Analog and Digital Signal Processing, Vol. 45, No. 2, pp. 217-226, 1998.

[29] S.P. Kosbatwar and S.K. Pathan, "Pattern Association for Character Recognition by Back-Propagation Algorithm Using Neural Network Approach," International Journal of Computer Science and Engineering Survey, Vol. 3, No. 1, pp. 127-134, 2012.

[30] M.A. Hossain, M.M. Rahman, U.K. Prodhan, and M.F. Khan, "Implementation of Back-Propagation Neural Network for Isolated Bangla Speech Recognition," International Journal of Information Sciences and Techniques (IJIST), Vol. 3, No. 4, pp. 1-9, 2013. 